\title{
El coraje como virtud fundamental del sujeto político ${ }^{2}$
}

\author{
The courage as a fundamental virtue of the political subject \\ A coragem como virtude fundamental do sujeito politico
}

\begin{abstract}
Resumen
El presente texto aborda las nociones de sujeto político y ciudadanía desde las posibilidades de militancia y respuesta a la violencia y la realidad. El debate planteado se enriquece con planteamientos de Michel Foucault, Hannah Arendt, Jacques Ranciere, Howard Zinn y Henry Thoureau. De igual modo, la reflexión sobre la experiencia de Mohandas Gandhi nutre la discusión por cuanto la no-violencia es un posicionamiento legítimo frente a las acciones violentas.
\end{abstract}

Palabras clave: sujeto político, ciudadanía, no-violencia, militancia.

Recibido: 7 de marzo de 2016, evaluado: 14 de abril de 2016, aprobado: 17 de abril de 2016

1 Director de Investigaciones, Corporación Universitaria Minuto de Dios —Uniminuto—, Sede Principal. Correo electrónico: cgjuliao@gmail.com

2 Algunas ideas de este texto se presentaron también en Bucaramanga, el 20 de mayo de 2016, en el marco del I Foro "Rol de la academia dentro del proceso de Paz y Posconflicto", organizado por las IES, Uniminuto, ESAP y UTS. 


\begin{abstract}
The present text addresses the notions of political subject and citizenship from the possibilities of militancy and counterviolence and the reality. The formulated debate enrichens with the expositions of Michael Foucault, Hannah Arendt, Jacques Ranciere, Howard Zinn and Henry Thoureau. In the same way, the reflection about Mohandas Gandhi experience nourish the discussion since the non-violence appears as a legitimate positioning against the violent actions.
\end{abstract}

Keywords: political subject, citizenship, non-violence, militancy.

\title{
Resumo
}

O presente texto aborda as noções de sujeito político e cidadania desde as possibilidades da militância e resposta à violência e a realidade. O debate proposto enriquece-se com propostas de Michel Foucault, Hannah Arendt, Jacques Ranciere, Howard Zinn e Henry Thoureau. Do mesmo jeito, a reflexão sobre a experiência de Mohandas Gandhi nutre a discussão porquanto a não-violência é um posicionamento legítimo em frente às ações violentas.

Palavras-chave: sujeito político, cidadania, não-violência, militancia. 


\section{Introducción}

\section{Valentia es hacer algo peligroso sin pensar. Coraje es caminar hacia el peligro, a sabiendas de los riesgos. \\ Gayle Forman}

Las palabras tienen gran importancia, hasta su última sílaba. Abordar la cuestión del sujeto político desde el ángulo de la subjetivación y no del de la subjetividad tiene sentido. La noción de subjetivación implica pensar al sujeto como un proceso, un proyecto siempre en curso, y no como algo dado, como si se tratara de un estado ya alcanzado y acabado. El sujeto político está en construcción permanente. El ciudadano no es un producto del cual podemos constatar su existencia, sino un proyecto que hay que producir.

Desde ahí se plantea la cuestión de las formas de la subjetivación política: ¿cómo generar ciudadanía ${ }^{3}$ ? ¿Qué camino emprender para llegar a ser un sujeto político? La cuestión debe ser mejor formulada: no se trata de "producir" un ciudadano mediante un mecanismo de fabricación externo al individuo. Al contrario, corresponde a cada uno escalar de la condición de animal social a la de animal político, del estado de sujeto responsable a la de sujeto soberano, de animal laborans a zoon politikon. El desafío entonces es situar el lugar del paso del estado prepolítico al político. Una manera de resolver esta cuestión y de identificar el proceso por el cual un individuo se compromete con su propio desarrollo ciudadano es entender el proceso de subjetivación política como aquello que diferencia un sujeto político de un sujeto prepolítico. Dicho de otro modo, ¿cuál es la virtud ciudadana esencial a adquirir? Siguiendo a Hannah Arendt y toda una tradición filosófica que optó por pensar lo político a partir de la acción, se sostiene aquí que esta virtud es el coraje.
El proceso de subjetivación política nos conduce entonces a la noción de coraje, entendida en sentido político, como virtud cardinal del ciudadano y como elemento que diferencia a los ciudadanos de los no-ciudadanos. Apoyándonos siempre en una filosofía política de la acción, podemos definir el coraje como aquello que hace pasar a un individuo de la inteligencia y comprensión de un problema a la voluntad praxeológica de resolverlo. Thoreau escribió: "Hay miles de personas que por principio se oponen a la esclavitud y a la guerra pero que, en la práctica, no hacen nada para acabarlas" (2007, p. 27). El coraje es, así, lo que elimina la distancia entre la comprensión de un problema y la decisión de actuar para solucionarlo. Ahora bien, un posible obstáculo a la acción reside en el hecho de que "las personas son pragmáticas. Quieren el cambio, pero se sienten desarmadas, solas, y temen ser la brizna de hierba que sobresale y será, por lo tanto, cortada de primero. Esperan a alguien que dé el primer paso" (Zinn, 2006, p. 14). El ciudadano es ese hombre del "primer paso", aquel que le apuesta a que si actúa de primero, otros lo seguirán lo suficientemente rápido para impedir que todos sean eliminados.

Ciudadano es aquel que tiene el coraje de transformar sus palabras en actos, sus pensamientos en compromiso, su posición intelectual en convicción real; en definitiva, aquel que pasa de la indignación a la movilización. Cuando decimos que el coraje consiste en pasar de la palabra a los actos tenemos conciencia de que ciertas formas del discurso ya son actos en sí mismos y, por lo tanto, que ciertas palabras son valientes; por ejemplo, el hecho de denunciar públicamente una injusticia rompiendo "la ley del silencio". Por ende, lo que aquí se llama "el paso de la palabra a los actos" designa el paso de una palabra timorata, que se dice en los círculos restringidos de la esfera privada, a una palabra política que afirma, abierta y públicamente, lo que denuncia ${ }^{3}$. Así mismo, la acción política puede ser

3 Si no distinguimos al "sujeto político" del "ciudadano es porque, a diferencia del enfoque jurídico-liberal, rechazamos ver la ciudadanía como un estatus jurídico; se trata de praxis. Es ciudadano aquel que actúa. La ciudadanía no es adquirida ni dada sino que le llega a quien se compromete públicamente.

4 Hay que recordar también que ciertas palabras, en virtud de su dimensión performativa, son, por sí, actos. 
un pensamiento porque hay pensamientos que son tan radicales y liberados de las normas establecidas que en sí mismos son valientes.

El coraje invita de ese modo a la acción, nos hace penetrar en el espacio público. Y es el propio ciudadano quien debe inscribir su acción en ese espacio público, liberar sus convicciones de la prisión de su pensamiento para dejarlas exponerse a todos y encarnarse praxeológicamente en actos concretos. El sujeto político prueba su coraje saliendo de los bastidores para pasar al frente de la escena política. Frédéric Gros escribe que "el coraje es principalmente exponerse, en el sentido de que sólo hay verdadero coraje cuando se exterioriza" (2006, p. 22). El coraje es una virtud exterior - exterioridad no se entiende peyorativamente como superficialidad o apariencia engañosa- en el sentido de que como intención no vale nada porque él es precisamente actualización y realización de la intención. El coraje se demuestra en la confrontación con lo real. “A los valientes en palabras los conocemos bien: son los más flojos en el terreno. Dejan a los otros hablar y ellos se callan" (p. 24).

Finalmente, hay que resaltarlo, el coraje se ejerce siempre en el marco de la gratuidad. El ciudadano valiente no espera por su gesto la menor recompensa o gratificación. No podría encontrar la motivación de su acto en una retribución financiera. Porque en ese caso el ideal del coraje quedaría empañado para siempre y hablaríamos más bien de un hombre celoso o un empleado dedicado que de un ciudadano valiente.

Ya con esta definición general del coraje hay que ir ahora más lejos. El coraje no es una noción monolítica y unificada. En efecto, la modernidad política, tanto a nivel de la práctica como de las ideas, nos permite establecer una tipología tripartita de las diferentes formas de coraje: el coraje de la verdad, que siguiendo a Foucault llamaremos parresia; el coraje de la libertad, que siguiendo a Arendt llamaremos heroísmo; y el coraje de la no-violencia, que siguiendo a Gandhi llamaremos satyagraha. La parresia es el coraje de decir lo verdadero en un mundo de mentiras y de "hacer de la propia vida un testimonio de la verdad". El heroísmo es el coraje de preferir la muerte a la servidumbre en el sentido de que, como lo decía el revolucionario mexicano Emiliano Zapata, "mejor vale morir parado que vivir de rodillas”. Finalmente, el satyagraha es el coraje de "combatir el mal rechazando imitar su violencia”.

A cada una de estas formas de coraje corresponde una figura de la subjetivación política: el militante para el coraje de la verdad, el revolucionario con su coraje de la libertad y el desobediente que manifiesta el coraje de la no-violencia. Para ilustrar mejor estas categorías nos referiremos, respectivamente, a tres personajes históricos: Simone Weil como arquetipo del militante — verdad-, George Orwell como modelo del revolucionario - libertad-, y Mohandas K. Gandhi como ejemplo del desobediente - no-violencia-.

\section{La parresia política -militancia de lo veraz-: hacer de la propia vida un "testimonio de la verdad"}

En sus últimos cursos en el Collège de France, entre 1983 y 1984, Foucault retoma una forma particular de existencia que, desde los cínicos griegos (2008, pp. 51-60), consiste en hacer de la propia vida una defensa de la verdad, así sea escandalosamente. Todos recordamos a Diógenes, viviendo en su barril, masturbándose en público y tratando al rey Alejandro de bastardo cuando éste vino a visitarlo. Se trata, desde ese comportamiento indignante, de adoptar una postura ética haciendo de la propia vida un "testimonio de la verdad". Desde ahí Foucault plantea la función del "decir-veraz" - parresia - en lo político. Su tesis es la siguiente: la parresia - entendida como el coraje de decir la verdad- y la democracia han mantenido siempre un lazo íntimo. En su curso del 2 febrero de 1983, Foucault explica que la democracia ateniense reposa en ciertos principios: la isonomía, obviamente, es decir, la igualdad de la ley para todos y la igualdad de todos ante la ley; y la isegoría, también, que designa la igual libertad de palabra: sea cual sea su oficio y su posición social cada ciudadano es libre de expresar su opinión a la asamblea. 
No obstante, al régimen de la "palabra democrática”, Foucault añade otra dimensión. La palabra libre e igual -isegoria - debe ir acompañada de la "palabra veraz", del hablar franco, del coraje de expresar públicamente lo que molesta, lo que no es agradable oír pero que debe ser dicho. La parresia se define, entonces, como la toma de la palabra de un hombre valiente que, rechazando la complacencia y la adulación, decide decir al pueblo la verdad, cualquiera que sea el precio - para el pueblo, pero sobre todo para él mismo-.

El estilo de vida del hombre valiente, que no duda en tomar la palabra para hacer escuchar la verdad, ha sido constante en el curso de la historia. El ascetismo cristiano medieval ${ }^{5}$ ha sido, según Foucault, el vehículo que ha transmitido de los antiguos a los modernos este modo de existencia iniciado por los cínicos. En estos tiempos, la modernidad occidental nos ofrece una figura arquetípica del coraje de la verdad: el militante político. Pero aquí tomamos distancia de Foucault que identifica, equivocadamente, al militante con el revolucionario. En efecto, para nosotros, el militante remite al orden de lo revolucionario, se contenta con poco y no invierte suficientemente en la causa de la verdad. El militante es aquel que, como Simone Weil, no solo denuncia la abominación del capitalismo imperialista y la barbarie de los franquistas; esta verdad es bastante fácil de decir, la denuncia es tan evidente que explicitarla no hace que la verdad avance. Millones de revolucionarios de toda clase - anarquistas, trotskistas, comunistas - fueron conscientes de la alianza entre "fascismo y gran capital" (Guerin, 1945) y combatieron sus efectos bárbaros. Pero la verdad que afirma el militante es mucho más profunda y exige un coraje real porque concierne al propio campo del militante, se dirige a sus amigos más cercanos. Esta verdad es autocritica; es, como lo dice Simone Weil, una “reflexión para desagradar". (1960, pp. 218-219)

$\mathrm{Y}$ es así porque incluso entre los suyos, sobre todo entre los suyos, el militante es mal visto; sacrifica su reputación en el altar de la verdad y de la justicia y, por su gesto de valentía, se expone directamente a la exclusión y la marginalización. Es estigmatizado porque es el más fiel a la causa y el más crítico frente a las armas implementadas para ésta. El militante, por su feroz apego a la verdad, no deja nunca de perturbar la buena conciencia del revolucionario quien, poniéndose del lado de los dominados, se cree salvado de toda crítica.

Ahora bien, el militante, que enciende con valor revolucionario su compromiso con la verdad, no debe identificarse con la figura del partidario. Este último es aquel que, creyendo hacer militancia, demuestra su amor por la verdad comprometiéndose con un partido político. Pero, debemos distinguir radicalmente el espíritu militante del espíritu partidario: la diferencia reside en el modo de pensar los problemas políticos y en la forma de reflexionar en general. Uno y otro orientan su razonamiento hacia la verdad pero mientras el militante se mueve correctamente en el universo del pensamiento, el partidario avanza como un cojo con los ojos vendados. El problema con los partidarios, escribe Simone Weil, es que "se ha llegado a pensar, en cualquier dominio, solo tomando posición "a favor" o "contra" una opinión. Después se buscan los argumentos, según el caso, sea a favor, sea en contra" (2007, p. 69). Este es el exacto resultado de la adhesión a un partido. Así, en ese espíritu partidario hay dos errores intelectuales. El primero es tomar primero posición y después justificarla. Una investigación racional, realmente preocupada por la verdad, debe proceder a la inversa. La tarea preliminar consiste en recolectar, seleccionar, clasificar y organizar la información. Y solamente después es posible formarse una opinión racional, conforme —en la medida de lo humanamente posible - a la verdad. Pero en casi todas partes la operación de tomar partido, de tomar posición a favor o en contra, substituye al ejercicio del pensamiento.

La segunda tara del espíritu partidario es que, abordando sistemáticamente los problemas de modo binario - a favor, en contra-, no los ve en toda

5 Para un estudio de los movimientos cristianos milenaristas de la Edad Media, que dan cuerpo a la verdad del Cristo a través de sus prácticas ascéticas y místicas, ver la obra de Cohn (1962). 
su complejidad, lo que requiere a menudo un acercamiento por otra vía. Hay que comprender que la parresia no es sólo coraje en acto - encarnar la verdad a la manera de los cínicos griegos- o en palabra - decir públicamente la verdad que molesta-: ella es también un coraje en pensamiento. Se trata entonces de mostrar coraje intelectual para no caer en el simplismo del espíritu partidario. Reflexionar a la manera de un militante, es decir, como cazador avezado de la verdad, no es tarea para flojos. Requiere un esfuerzo del cual solo el militante valiente es capaz. Es fácil y tentador evadir la reflexión adhiriéndose sin crítica a las posiciones que el partido nos define porque, como lo escribe Simone Weil, "nada es más confortable que no pensar” (2007, p. 60). Nada más cobarde, añadimos nosotros.

Habiendo de este modo trazado a grandes rasgos la figura del militante y de la parresia que encarna, hay que precisar que el coraje de la verdad no necesariamente es la verdad del coraje. Dicho de otro modo, la modernidad política propone otras variantes del coraje. La primera es la del heroísmo, el coraje de la libertad.

\section{El heroísmo del revolucionario: "mejor morir de pie que vivir de rodillas"}

El heroísmo teorizado por Arendt, sobre todo en ¿Qué es la política?, se fundamenta en el coraje y el amor por la libertad de aquel que prefiere la muerte a la servidumbre. Así, ella escribe: "sólo puede ser libre aquel que está dispuesto a arriesgar su vida" (2005, p. 83). Saber superar el miedo a la muerte para penetrar en el espacio público es probar el coraje, "la primera de todas las virtudes políticas" (p. 83). El héroe, en nombre de la libertad, supera su miedo a la muerte y osa exponerse públicamente pese a los riesgos que ello implica.
Pasar de las penumbras de la esfera privada a los proyectores del espacio público pasa de modo repentino, es un salto hacia adelante ${ }^{6}$.

El coraje de la libertad, que surge en la polis griega, concierne también al revolucionario de los tiempos modernos. Pero hablar hoy de revolución genera sospecha de las peores atrocidades. Por lo tanto, no sorprende que algunos expresen sus temores frente a la inclinación totalitaria del héroe arendtiano. "El siglo xx ha conocido formas de heroísmo totalitario, sea en la exaltación del soldado que busca la movilización total, sea en la glorificación del hombre nuevo" (Abensour, 2007, p. 257). Pero hay que precisar que el héroe de Arendt, lejos de amenazar lo político - como lo hace el totalitarismo, que es destrucción y no exceso de lo político-, se revela en y para la polis. Es esta cualidad política del heroísmo lo que le impide caer en la tiranía pues lo propio de ciertas formas de heroísmo, por ejemplo estético o metafísico, es reforzar la premisa desigualitaria y favorecer la dominación de una minoría. Pero en Arendt el carácter político del heroísmo significa que éste se despliega en los límites de la condición humana. El héroe arendtiano no tiene nada de superhombre; estamos, por tanto, frente a un heroísmo radicalmente nuevo: un heroísmo al alcance de todos. El coraje de la libertad - porque la libertad es un deseo que habita en la naturaleza humana y, por lo tanto, en cada uno de nosotros- es un heroísmo del "no importa qué”, en el sentido de Rancière7; así, Arendt reconcilia heroísmo y democracia. Precisemos por último que ese heroísmo, además de ser accesible a todos, se manifiesta entre varios, como experiencia de pluralidad. La subjetivación política siempre es cuestión de un "nosotros", nunca de un "yo". Por eso, el heroísmo de los revolucionarios es el opuesto de aquel heroísmo solitario de un De Gaulle o de un James Bond. Se trata de una forma de coraje nuevo y paradójico que, según la feliz formula de

6 Seguimo aquí el trabajo de Miguel Abensour sobre el heroísmo revolucionario en Arendt. Ver Abensour (2007, pp. 257-263).

7 Hay que referirse sobre todo a su obra El maestro ignorante (Rancière, 2003) donde este autor dice, en boca de Jacotot, entre otras cosas y para horror de los pedagogos, que no hace falta saber para enseñar. Su crítica asume dos líneas: por un lado, la educación escolar es vista como embrutecimiento, en contra del mito pedagógico que siempre se creyó era igualitaria y emancipadora; y por otro, se cuestiona la figura del intelectual crítico como reproductor de la misma desigualdad que critica. 
Abensour, podemos llamar "heroísmo de los sin nombre". Porque, como lo han señalado sus contemporáneos, "¿quién conoce esos héroes que en 1848 o en 1871 tomaron la iniciativa de un asalto o resistieron hasta la muerte en las barricadas, frente a las fuerzas de la represión?” (2007, p. 262).

Pero esta presentación algo idílica del heroísmo revolucionario no debe ocultar su cariz problemático. Haciendo primar la libertad en la vida humana, puesto que de eso se trata la máxima "mejor morir de pie que vivir arrodillado", el revolucionario penetra un espacio inestable donde existe el riesgo permanente de caer en el nihilismo. El revolucionario está dispuesto, si es necesario, a sacrificar su vida, incluso la de otros, para salvaguardar la libertad. Esta disposición no es muy deseable porque, como explica Camus, es asumir una concepción absolutista de la libertad según la cual si la libertad no es total la vida no vale la pena ser vivida. Ahora bien, la libertad absoluta, añade Camus, "es el derecho de dominar, para el más fuerte” (1953, p. 259). La máxima libertad siempre firma la sentencia de muerte de la justicia.

Esta búsqueda de la "consagración exclusiva" de la libertad Camus la llama el "Todo o Nada". El héroe revolucionario que se adhiere al "Todo o Nada" se equivoca. Traiciona su vocación original. Luchando por una libertad total, ilimitada, que no admite ninguna frontera, ni siquiera la libertad del otro, cree manifestar coraje, mientras que solo demuestra su locura. El espíritu revolucionario, si quiere lograr su objetivo, debe proponer una versión relativa y restringida de la libertad. En efecto, y así lo propone Arendt, el heroísmo sólo es bienvenido cuando es humano, es decir, cuando reconoce su finitud. Sólo un coraje mesurado puede ser auténtico; de otro modo estaríamos en un simulacro de coraje, una forma de martirio o de sacrificio. Si se olvida el principio de limitación el héroe bascula en la lógica del "Todo o Nada" y desemboca en un nihilismo destructor. Para evitarlo, la revolución debe fundar una filosofía de los límites y de lo relativo manteniendo una tensión permanente entre las parejas nocionales para no absolutizar ninguno de los dos elementos en detrimento del otro. Se trata de salvaguardar ese equilibrio precario entre rechazo y consentimiento, singularidad y universalidad, individuo e historia y, sobre todo, entre libertad y vida. Es al precio de ese esfuerzo intelectual de cada instante que el revolucionario evitará convertirse en torturador.

Sin embargo, no hay que equivocarse: el verdadero héroe no desprecia la vida. Está dispuesto a sacrificarla por la libertad, pero la ama como lo más precioso; porque no hay ningún mérito en dar la vida cuando no se la ama (Gros, 2006, p. 43). Lo que es admirable en este coraje es, precisamente, que se renuncia a aquello por lo que se lucha: la vida humana. Añadamos que el héroe no es aquel que no tiene miedo, sino aquel que sabe reconocer su temor a la muerte superándolo y encontrando los recursos mentales para ver más allá, para comprender que su muerte tiene un sentido si se dirige hacia la libertad. Así, el heroísmo revolucionario no es cuestión de no tener nunca miedo - eso es lo propio del confiado y del naïf- sino de afrontar su miedo - eso es lo propio del intrépido que, etimológicamente, es el que no tiembla ante el peligro-. Ahí aparece una exigencia que depende más de la fuerza interior que de la fuerza física: el dominio de sí, que se ejerce a varios niveles - contener los miedos y pasiones, reducir las cóleras y debilidades- y requiere un aprendizaje. El control de sí mismo no se adquiere sino por la perseverancia y la aplicación repetida de una serie de ejercicios: "Doroteo de Gaza recomienda comenzar por habituarse a quitar pequeñas cosas, una vana curiosidad, una palabra inútil, para prepararse poco a poco a mayores sacrificios" (Hadot, 2000, p. 367). $\mathrm{Al}$ término de una amplia "terapéutica de las pasiones", el héroe, dueño de sí, es apto para combatir por la libertad hasta el límite de su vida.

Queremos recordar que no hay que pensar en el héroe como un gran hombre o como un ser extraordinario, mitológico, semidiós y medio-hombre. El término, tal como hemos recon-ceptualizado, designa ante todo a esos héroes anónimos que, desde los "sansculottes" franceses y los "comuneros" colombianos hasta los "zapatistas" mexicanos, hacen vivir las revoluciones modernas. Asimismo, 
para terminar de conformar esta figura y, finalmente, dar paradójicamente un nombre a ese "heroísmo de los sin nombre", queremos concluir con la historia de George Orwell. Cuando, durante la Guerra Civil Española Orwell, Orwell se compromete en las milicias del POUM ${ }^{8}$ aún no es un personaje célebre. A los ojos de sus camaradas él es su igual, Eric Blair, su verdadero nombre, un hombre entre tantos otros. Y, precisamente, porque es aún anónimo, es que su experiencia española nos interesa. Inglés de origen indio, nada lo predestinaba a portar el fusil en la Cataluña de 1936 salvo su conversión al "socialismo democrático" cuando entra en contacto con los mineros británicos. Nada lo predestinaba, nada lo obligaba a más. De origen burgués y sin ningún lazo con España, hubiera sido fácilmente comprensible que Orwell prefiriera conservar su empleo de librero y seguir viviendo tranquilamente en Londres. Pero si eligió el no confort de la guerra y el riesgo de la muerte es porque una fuerza lo impulsaba a actuar y una causa lo presionaba a comprometerse: la libertad. Como lo escribe en Hommage a la Catalogne, sólo fue a España con la intención de escribir algunos artículos. Pero una vez allá, constatando que los anarquistas tenían la sartén por el mango en Cataluña y que la revolución tenía su propio ritmo, le parece "inconcebible poder actuar de otra forma" que no fuera comprometerse con las milicias (1982, pp. 12-13). En dos ocasiones estuvo a punto de perder la vida. Pero la intensidad de dicha amenaza no bastó para hacer renunciar al revolucionario que crecía en él; reinaba en Barcelona y en el corazón de Orwell "la fe en la revolución y [...] la impresión de desembocar pronto en una era de igualdad y de libertad" (p. 15). Esta idea de una sociedad sin clases era para Orwell una causa que merece ampliamente que se "arriesgue la piel por ella” (p. 111). Dicho esto, nos parece que la experiencia catalana de Orwell constituye un ejemplo representativo de lo que llamamos "coraje de la liberta”. L'Hommage a la Catalogne debe evidentemente ser leído con una mirada especialmente más crítica que si se tratara de una autobiografía, pero en ese relato hallamos el conjunto de los componentes que caracterizan la figura del héroe revolucionario.
El satyagraha, el coraje de la noviolencia: "resistir al mal sin caer en la violencia"

La no-violencia no es una negación del conflicto sino la voluntad de participar en él de otra forma diferente a la violencia. Lo que llamamos "coraje de la no-violencia" es la fuerza para resistirse que rechaza imitar la violencia del adversario. Hay algo sorprendente en la aparición de fenómenos de resistencia no-violenta o de desobediencia civil. Expliquémonos. Luchar sin armas contra un adversario armado no es algo obvio. Frente al agresor — sea un ocupante, un dictador, u otro-, el agredido dispone de tres opciones: la colaboración, la pasividad, o la resistencia. La tercera opción es la más peligrosa pues la resistencia, una vez que uno se ha comprometido, puede ser manejada de dos formas: con las armas o sin ellas. Aquellos que resisten sin armas - los desobedientes- lo hacen a menudo por falta de algo mejor, simplemente porque no tienen armas a disposición y no tanto por convicción moral. Pero poco importa, lo incomprensible está en esto: ¿cómo un grupo de individuos desarmados decide resistir o actuar contra un adversario que, él sí, dispone de armas y no dudará, si es necesario, de usarlas? Tal compromiso exige un doble coraje: el de decir "no", de resistir, y resistir sin armas, es decir, teniendo conciencia de la disimetría de medios que lo opone a su adversario.

El coraje no es una dimensión optativa de la noviolencia. Al contrario, hay que insistir en el hecho de que la no-violencia, en el sentido en que es una técnica de lucha, no funcionaría sin el coraje que le es propio pues es inmoral resolver un conflicto por la fuerza física. Gandhi siempre lo ha repetido, "el objetivo del desobediente consiste en convertir, no en constreñir, a aquel que hace el mal” (2007, p. 140). Pero la experiencia enseñó a Gandhi que la persuasión mediante la razón a menudo fracasa; lo podemos constatar en lo cotidiano. En esas condiciones, ¿cómo convencer al adversario político de que está en el error? ¿Qué otro mecanismo permite la persuasión? Gandhi responde: llegar al

8 Partido Obrero de Unificación Marxista, de tendencia trotskista. 
corazón: "para obtener un resultado decisivo [explica] no basta convencer a la razón; hace falta igualmente tocar el corazón" (1990, p. 162). El llamado al corazón funciona como una alternativa o un agregado positivo al llamado a la razón. Cuando la tentativa de persuasión mediante el discurso racional ha fracasado, los oponentes pueden intentar usar medios de persuasión no racionales.

Entonces surge la cuestión siguiente: ¿cómo tocar el corazón puede convertir a aquel que está en el error cuando la razón ha fracasado? Por el sufrimiento personal que se infringe al inocente, responde Gandhi. Aceptando voluntariamente sufrir por su posición moral, el desobediente demuestra su fuerza de convicción y excede el simple terreno del discurso racional que no exige ningún coraje particular. Hay que sacrificarse para tocar el corazón del adversario y despertar su conciencia adormecida. Según Gandhi, a aquel que me golpea yo debo, como Jesús lo enseña, ofrecer la otra mejilla; es posible, explica Muller, "que rehusarse a imitar la violencia del adversario lo sorprenda, ya que pensando merecer una respuesta, lo desconcierta y finalmente lo desarma" (1994, pp. 33-34). Porque, anota Gandhi, "no hay satisfacción en matar a aquel que recibe bien la muerte; por eso los soldados aman atacar al enemigo cuando él responde a los golpes con golpes y a la violencia con violencia" (como se cita en Muller, 1994, p. 34); y añade:

Yo busco despuntar completamente la espada del tirano, no atacándolo con un acero mejor afilado, sino engañando su expectativa de verme ofrecer una resistencia física. Encontrará en mí una resistencia del alma que sale de su alcance. Esta resistencia primero lo enceguecerá y después lo obligará a inclinarse (Gandhi, 1960, p. 110).

Aquel que ofrece su persona en sacrificio desarma así toda hostilidad. El sufrimiento tiene el poder de convertir las razones más sordas y los corazones más endurecidos ${ }^{9}$. Así, el coraje de la no-violencia es una condición de efectividad del satyagraha - acción no-violenta-. Para persuadir al adversario que se halla en el error, el desobediente debe valientemente oponerse sin violencia. El sufrimiento inocente del desobediente permite convertir al adversario más que constreñirlo.

Es útil recordar aquí las palabras severas de Arendt contra esta idea de Gandhi de que el sacrificio sería una prueba de nuestra convicción y un testimonio de coraje:

Es lamentable que tantas personas sean persuadidas de que la "voluntad de sacrificarse a sí mismo" constituye la mejor prueba de "la intensidad del compromiso" y de la seriedad de "aquel que desobedece por fidelidad a una ley", porque esta forma de fanatismo únicamente logra su objetivo en los excéntricos y, de toda forma, tiene como efecto hacer imposible una discusión racional de los datos del problema (1972, p. 69).

En el mismo sentido, Max Weber y la Iglesia católica recuerdan que la ética del Sermón de la montaña no vale sino en las relaciones entre individuos, pero no entre grupos y naciones. Ofrecer la otra mejilla sería, según ellos, una máxima estrictamente ética y para nada destinada a la política. Pero la audacia de Gandhi y el coraje de la no-violencia es precisamente politizar esta máxima. Esta politización presenta un doble interés: permite, de una parte, reintroducir un poco de ética en el universo frio y cínico de la política; por otra, valida un método innovador de resolución de conflictos: la acción no-violenta. Precisemos, por último, contra lo que se dice a menudo, que no hay autodestrucción en el gesto de presentar la segunda mejilla. El masoquismo sería ofrecer la misma mejilla.

9 Bakunin pensaba que era mejor apelar a la consciencia del individuo que a su razón pues la razón puede ser un obstáculo para la acción: supone la división interna y la inhabilidad para actuar. El análisis racional, porque no tiene fin, paraliza la acción. La consciencia, al contrario, se preocupa por generar más una acción eficaz que un pensamiento puro. 
Gandhi, si bien considera que el más exigente de los corajes es el de la no-violencia, sabe reconocer la presencia de una cierta forma de valentía en la violencia. A menudo repite que "allá donde la opción es solamente entre la cobardía y la violencia, hay que decidirse por la solución violenta" (1990, p. 182) pues, ya que es imposible que un cobarde se convierta en no-violento, eso no es imposible para un hombre violento (p. 179). Aquel que defiende la justicia con las armas posee en efecto, contrariamente a aquel que huye, una virtud necesaria para poder llegar a ser un día no-violento: el coraje. Afirmando que la violencia, dado que es valerosa, vale mejor que la cobardía, Gandhi se aleja de los pacifistas. Estos últimos, en efecto, adoptan una posición absolutista que los conduce a hacer de la negación de partir a la guerra una máxima moral intangible. Gandhi admite, al contrario, que es necesario - en situaciones bien particularesparticipar. Así, el coraje de la no-violencia parece incompatible con la postura pacifista que, para algunos, es una forma de cobardía.

El coraje de la no-violencia, como se ha dicho del de la verdad y de la libertad, se conjuga también a nivel intelectual. La filosofía de la no-violencia es coraje intelectual al rechazar la ideología de la violencia legítima que afirma evidentemente que la violencia, sea legítima o no, siempre es legítima. Lo que se postula y a lo que se opone frontalmente la filosofía de la no-violencia es a que la violencia es legítima cuando sirve a una causa justa. El desafío es romper con la ideología de la violencia que ejerce "un verdadero chantaje en los ciudadanos al afirmar que la única forma de ser valientes es ser violentos y llamarlos cobardes si no lo son" (Muller, 2005, p. 77). Frente a la cuestión de los conflictos - ¿cuál actitud adoptar ante un conflicto dado?- la ideología de la violencia legítima plantea una alternativa dualista - actuar violentamente o retirarse cobardementey denuncia la cobardía, llegando así, indirectamente, a una legitimación de la violencia. Es cierto que, frente a un conflicto extraño, tenemos siempre que elegir entre intervenir o mantenernos alejados; pero es falso que la única intervención posible sea de naturaleza violenta. Pensar las cosas desde ese ángulo, rechazando la alternativa binaria violencia/ cobardía e introduciendo la posibilidad de una acción no-violenta, es mostrar coraje intelectual porque esta operación del espíritu va en contra de la cultura dominante que no deja de producir sutiles retóricas argumentativas destinadas a justificar el uso de la violencia. Y decimos "sutiles" porque la cultura dominante no se presenta abiertamente como cultura de la violencia legítima.

Por tanto, hay que admitir que las sociedades occidentales reposan sobre el principio de que la violencia se justifica a condición de que sirva a la justicia. Tal es el presupuesto ético de las doctrinas universalmente admitidas - e invocadas- de la legítima defensa, de la guerra justa y de la razón de Estado. La filosofía de la no-violencia, rechazando esta ideología de la violencia legítima, demuestra su independencia de espíritu y una cierta forma de coraje intelectual.

\section{Conclusión: ¿El desobediente puede ser un militante o un revolucionario?}

Hemos delineado las tres figuras del coraje político: el militante que defiende la verdad, el revolucionario luchando por la libertad y el desobediente que actúa para la no-violencia. Este esfuerzo de conceptualización sólo tiene sentido porque plantea nuevas problemáticas; dos preguntas sobre todo: ¿el desobediente puede ser un militante?, y, ¿puede ser un revolucionario? Se trata de interrogantes bien distintos. El primero nos lleva a confrontar las nociones de no-violencia y de verdad y a evaluar su compatibilidad. El segundo plantea un problema crucial, aunque poco abordado, común a todos los pensamientos emancipadores: ¿la noción de revolución es pensable independientemente de la de violencia? Sólo explicitaremos esas dos problemáticas, cuya elucidación completa amerita más que esta breve conclusión.

Clarificar la relación entre el desobediente y el militante es confrontar la no-violencia con la verdad porque la primera es al primero lo que la segunda al segundo: su forma específica de coraje. Esta confrontación podría ser elaborada desde el 
pensamiento gandhiano porque es ahí donde nació y donde ha sido mejor teorizada. La sociedad política es, según Gandhi, el espacio de reencuentro y confrontación de diferentes pretensiones a la verdad, siendo cada pretensión correcta pero parcial. Además, los individuos no tienen conciencia de la dimensión relativa de su verdad. Ahora bien, la historia nos enseña que aquel que cree poseer la verdad absoluta es capaz de perpetrar horribles crímenes para defenderla ${ }^{10}$. La humanidad ha cometido las peores atrocidades "en nombre de la Verdad" - verdad religiosa, verdad de la historia, verdad de la raza, verdad de la ciencia-. La cuestión es, por lo tanto, la siguiente: ¿cómo Gandhi puede mantener su concepción de la política definida como búsqueda de la verdad, evitando un deslizamiento autoritario o anárquico de la actividad política? ¿Cómo garantizar la no-violencia exigiendo al mismo tiempo la búsqueda de la verdad?

De dos modos. Primero, por una distinción epistemológica entre verdad absoluta y verdades relativas: la verdad absoluta existe pero no podemos acceder a ella y, dado que no se pueden conocer sino verdades relativas, los individuos no tienen el derecho a juzgar al otro y mucho menos a castigarlo de forma violenta. Segundo, para que la búsqueda política de la Verdad sea no-violenta, es necesario que la Verdad y la no-violencia sean una sola cosa. Muller detalla este segundo punto:

La historia está ahí para testificar - y la experiencia lo confirma todos los días- que la verdad se convierte en un vector de violencia cuando se absolutiza y no está anclada en la exigencia de la no-violencia. Si la verdad no implica por sí misma la deslegitimación radical de la violencia, entonces llegará siempre un momento en el que la violencia aparezca como un medio legitimo para defender la verdad (2008, p. 139).

Gandhi, consciente de esta exigencia, había ligado sólidamente la no-violencia a la verdad de modo que esta última no termine en conflicto armado. Ambas son indispensables para:

[...] formar un todo único. Es por eso que, a veces, se las compara a las dos caras de una misma moneda. La una es indisociable del otro. Y el valor de la moneda es el mismo sin importar cual sea el lado que se $\operatorname{mira}^{11}$ (1990, p. 151).

¿El desobediente puede ser revolucionario? Esta segunda cuestión invita a reconceptualizar la noción de revolución no-violenta. El ciudadano ordinario y el investigador de ciencias sociales asocian instintivamente "violencia" y "revolución". Esta evidencia, sin embargo, debe ser cuestionada. El hecho de que, en los últimos cuarenta años, cincuenta de sesenta y siete reversiones de regímenes autoritarios han resultado gracias a la resistencia civil no-violenta lleva a redefinir la noción de revolución separándola de la de violencia. En suma, todo o casi todo ya ha sido dicho y experimentado del lado de la versión "violenta" de la revolución, una revolución no-violenta es históricamente posible, teóricamente concebible y, en dicho caso, ¿qué sentido dar a esta noción y cuáles son las características del fenómeno? Esas preocupaciones permitirán renovar la filosofía política contemporánea.

10 Hans Kelsen nos había advertido el lazo entre una epistemología de la verdad y la autocracia, de una parte, y entre una epistemología positivistarelativista y la democracia, de otra. Gandhi, en la misma época, percibía los riesgos de violencia inherentes a una política fundada sobre una verdad substancial. El riesgo es importante porque la búsqueda de la verdad culmina en la guerra santa de los tiempos modernos. La historia, escribe Gandhi, nos enseña que "millares de atrocidades han sido cometidas a nombre de Dios". Gandhi asegura no conocer "mayor pecado que oprimir al inocente a nombre de la verdad".

11 Así como la verdad está orgánicamente ligada a la no-violencia, la mentira lo estáa a la violencia. Así, en la controversia que opone a Kant y a Constant sobre el derecho de mentir, Gandhi se situaría al lado de Kant. 


\section{Referencias}

Abensour, M. (2007). Para una fllosofía politica critica. Barcelona: Siglo XXI

Arendt, H. (1972). "La désobéissance civile" en Du mensonge à la violence. Paris: Calmann-Lévy

Arendt, H. (2005). ¿Qué es la política? Barcelona: Paidos

Camus, A. (1953). El hombre rebelde. Buenos Aires: Losada

Foucault, M. (2008). "Le courage de la vérité: l'ascète, le révolutionnaire et l'artiste" en Esprit, Paris, pp. 51-60

Gandhi (1960). Lettre à l'ashram. Paris: Albin Michel

Gandhi (1990). Tous les hommes sont frères. Paris: Gallimard

Gandhi (2007). Résistance non-violente. Paris: Buchet/Chastel

Gros, F. (2006). Etats de violence, Essai sur le fin de la guerre. Paris: Gallimard
Guerin, D. (1945). Fascisme et Grand capital. Paris: Gallimard

Hadot, P. (2000). ¿Qué es la filosofía antigua? México: FCE

Muller, J-M. (1994). Gandhi, la sagesse de la nonviolence. Paris: Desclée de Brouwer

Muller, J-M. (2005). Dictionnaire de la non-violence. Gordes: Les Editions du Relié

Muller, J-M. (2008). Le courage de la non-violence: Paris: Les Editions du Relié

Orwell, G. (1982). Hommage à la Catalogne. Paris: Champ Libre

Thoreau, H. (2007). La désobéissance civile. Paris: Le passager clandestin

Weil, S. (1960). "Réflexions pour déplaire" en Ecrits historiques et politiques. Paris: Gallimard

Zinn, H. (2006). L'impossible neutralité. Marseille: Agone 